\title{
Misuse and Abuse of Interactive Technologies
}

\section{Antonella De Angeli}

School of Informatics, University of Manchester

PO Box 88, Manchester, M60 1QD, UK

Antonella.de-angeli@manchester.ac.uk

\section{Sheryl Brahnam}

Computer Information Systems, Missouri State University 901 S. National Street, Springfield, Missouri 65804, USA

sb@facescience.org

\section{Peter Wallis}

NPL Group, Department of Computer Science,

The University of Sheffield

Western Bank, Sheffield S10 2TN, UK

pwallis@acm.org

\section{Alan Dix}

Computing Department, InfoLab21, Lancaster University

Bailrigg, Lancaster, LA1 4YW, UK

alan@hcibook.com

\begin{abstract}
The goal of this workshop is to address the darker side of $\mathrm{HCl}$ by examining how computers sometimes bring about the expression of negative emotions. In

particular, we are interested in the phenomenon of human beings abusing computers. Such behavior can take many forms, ranging from the verbal abuse of conversational agents to physical attacks on the hardware. In some cases, particularly in the case of embodied conversational agents, there are questions about how the machine should respond to verbal assaults. This workshop is also interested in understanding the psychological underpinnings of negative behavior involving computers. In this regard, we are interested in exploring how $\mathrm{HCl}$ factors influence human-to-human abuse in computer-mediated communication. The overarching objective of this workshop is to sketch a research agenda on the topic of the misuse and abuse of interactive technologies that will lead to design solutions capable of protecting users and restraining disinhibited behaviors.
\end{abstract}

\section{Keywords}

Abuse, machine violence, mediated verbal abuse, user aggression, disinhibition 


\section{ACM Classification Keywords}

H.1.2 User/Machine Systems - Human factors, Software psychology, H.5.2 User Interfaces - Theory and methods, and K.4.2 Social Issues - Abuse and crime involving computers

\section{I ntroduction}

Current $\mathrm{HCl}$ research is witnessing a shift from a materialistic perspective of viewing the computer as a tool for cognition to an experiential vision where the computer is described as a medium for emotion. Until recently, scientific investigations into the user's emotional engagement in computing were relatively few.

Since the turn of the century, a number of $\mathrm{CHI}$ workshops have launched investigations into the emotional component of the user's computing experience. For example, the $\mathrm{CHI} 2002$ workshop Funology: Designing Enjoyment explored how fun and enjoyment could better be integrated into computer interface design. The organizers were puzzled by the fact that making computers fun to use had failed to generate significant interest despite Carroll's and Thomas's [1] call to the $\mathrm{HCl}$ community in 1988 for a systematic study of enjoyable computing. Current research in funology echoes Norman's [2] conclusions about aesthetics: fun matters-fun interfaces work better.

Unfortunately, enjoyment is not something added to an emotionally neutral computing experience. The user's experiences are colored by a host of emotions, many of them negative. Negative feelings do more than tarnish the user's experience, however. As Wensveen et. al., [3] noted, "In human-product communication people also express emotion (often negative); for instance,

they may shove a chair, bang a printer, or slam a door. While this behavior might offer some relief, it does not enhance communication or the experience. On the contrary, if we forcefully express our negative emotions we can break the product and diminish the beauty of interaction." (p. 60).

Abuse: The darker side of human-computer interaction [4] may well have been the first workshop explicitly to address negative emotions in computing and their behavioral consequences. The papers presented in that workshop demonstrated that interface design and metaphors can inadvertently rouse more than user dissatisfaction and angry reactions: they can promote a wide range of negative behaviors that are directed not only towards the machine but also towards other people.

An example of a metaphor that encourages abuse of the interface is the human-like interface, e.g., embodied conversational agents and automated voice systems. Although human-like interfaces are intended to make interaction with the computer more natural and socially engaging, examination of interaction logs demonstrates that users are prone to verbally abusing these interfaces [5]. In terms of promoting the abuse of other people, email, message boards, and chatrooms make it easy for people to engage in cyberbullying, flaming, and sexually embarrassing comments, accusations, and revelations.

In Abuse: The darker side of human-computer interaction, it was concluded that a comprehensive understanding of $\mathrm{HCl}$ factors that promote negative behaviors is necessary if we are to begin designing 
interfaces that enhance the user's computing experiences and encourage user collaboration with the interface and with other users.

Some primary goals of Use and Abuse of Interactive Technologies are to work out a definition of computermediated abuse that is relevant to $\mathrm{HCl}$, to define design factors that promote the misuse and abuse of interactive technologies, and to sketch a research agenda that will lead to design solutions capable of protecting users and restraining disinhibited behaviors.

\section{I ssues}

This workshop intends to analyze the phenomenon of computer-mediated abuse from several perspectives and with regard to different applications. The topic is likely to be of interest to a range of research streams in $\mathrm{HCl}$, including studies of computers as social actors, affective computing, and social analyses of online behavior. The purpose of this interdisciplinary workshop is to bring together researchers who have encountered instances of abusive behavior in $\mathrm{HCl}$, who might have given some thought to why and how it happens, and who have some ideas on how proactive, agent-based interfaces should respond. We expect to generate a debate on the subject of computer-mediated abuse, the abuse of agents as cultural artifacts, and the effect of abuse on the agent's task, believability, and, in general, on interface design. This discussion should provide a foundation for understanding the misuse and abuse of interactive technologies and for developing a systematic approach to designing interfaces that counter these abuses.

As software is evolving from the tool metaphor to the agent one, understanding the role of abuse in $\mathrm{HCl}$ and its effect on the task at hand becomes increasingly important. People tend to misuse and abuse tools, it is true, but no one expects a hammer (or a desktop) to respond. With the agent model, however, software can be autonomous and is expected to take responsibility for its actions. Conversational agents are a clear case of a software entity that might be expected to deal with user verbal assaults. Virtual assistants, to take a classic application instance, should not just provide timely information; a virtual assistant must also be a social actor and participate in the games people play. Some of these games appear to include abusive behavior.

At first glance, abusing the interface, as in the example above, might not appear to pose much of a problemnothing that could be accurately labeled abuse since computers are not people and thus not capable of being harmed. That the human abuse of human-like agents is not considered a serious problem is evidenced by the fact that the research literature is mostly silent about this issue. Nevertheless, the fact that abuse, or the threat of it, is part of the interaction, opens important moral, ethical and design issues. As machines begin to resemble people physically and behaviorally, it is important to ask how they should respond when verbally attacked. Is it appropriate for machines to ignore aggression? If agents do not acknowledge verbal abuse, will this only serve to aggravate the situation? If potential clients are abusing virtual business representatives, then to what extent are they abusing the businesses or the social groups the human-like interfaces represent?

Another concern is the potential that socially intelligent agents, especially embodied conversational agents, have of taking advantage of customers, especially 
children, who innocently attribute to these characters such warm human qualities as trustworthiness [6]. It is feared that these relationship-building agents could be used as a potent means of marketeering, branding, and advertising [7], dangerous for children and adults alike (take, for instance, the virtual girl friends offered at vgirl.com that are designed to probe men's spending habits, ply men for demographic information, and generate income by petulantly demanding virtual presents). Socially intelligent agents have the potential of exploiting our emotional needs and propensity for suspending disbelief.

In addition to the issues and questions posed above, some of the larger questions and issues we hope to address during the workshop are the following:

- How do the misuse and abuse of the interface affect the user's computing experience?

- How do different interface metaphors (embodied conversational characters, windows, desktop) shape a propensity to misuse or abuse the interface?

- What design factors trigger or restrain disinhibited behaviors?

- How does computer-mediated abuse differ from other forms of abuse, e.g., the abuse of people, symbols, flags, sacred objects, and personal property? Is it appropriate to use the term abuse in this context?

- Abuse can be a part of our social world. It is something we avoid. How can we develop machines that learn to avoid user abuses?

As the workshop is intended to be interdisciplinary, the questions and methodologies discussed will be of interest to a broad audience, including social scientists, psychologists, computer scientists, and those involved in the game industry. To help inform our questioning, we would also welcome philosophical and critical investigations into the abuse of computing artifacts.

\section{Pre and Post Workshop Activities}

Workshop papers and summaries of workshop discussions will be available at www.agentabuse.org, which also hosts a wiki where workshop participants and other interested parties can further discuss this topic.

In addition, other publishing venues are in consideration by the workshop organizers, and plans for another workshop are also being drafted.

\section{References}

[1] Carroll, J.M. and Thomas, J.C. Fun. SIGCHI Bulletin, Vol. 19: 3 (1988) 21-24.

[2] Norman, D.A. Emotion and Design: Atractive Things Work Better. Interactions, Vol. 4: (2002) 36-42. [3] Wensveen, S., Overbeeke, K., Djajadiningrat, T., and Kyffin, S. Freedom of Fun, Freedom of Interaction. Interactions, Vol. 11: 4 (2004) 59 - 61.

[4] Angeli, D.A., Brahnam, S., and Wallis, P. Abuse: The Darker Side of Human Computer Interaction. Interact 2005. Rome, I taly:(2005) 91-92.

[5] Angeli, D.A. and Carpenter, R. Stupid Computer! Abuse and Social Identity. Abuse: The Dark Side of Human-Computer Interaction: (2005) 19-25.

[6] Bickmore, T. and Picard, R. Establishing and Maintaining Long-Term Human-Computer Relationships. ACM Transactions on Computer Human Interaction (ToCHI), Vol. 12: 2 (2005) 293-327.

[7] Duck, S. Talking Relationships into Being. Journal of Social and Personal Relationships, Vol. 12: 4 (1995) 535- 540. 